Article

\title{
Are Issuer Margins Fairly Stated? Evidence from the Issuer Estimated Value for Retail Structured Products
}

\author{
Janis Bauer ${ }^{1}$, Holger Fink ${ }^{2,3, *}$ and Eva Stoller ${ }^{3}$ \\ 1 Institute for Finance \& Banking, Ludwig-Maximilians-Universität München, Ludwigstr. 28 RB, \\ 80539 Munich, Germany; mail@janisbauer.de \\ 2 Department of Computer Science and Mathematics, Munich University of Applied Sciences, Lothstr. 64, \\ 80335 Munich, Germany \\ 3 Center for Quantitative Risk Analysis, Department of Statistics, Ludwig-Maximilians-Universität München, \\ Akademiestr. 1/I, 80799 Munich, Germany \\ * Correspondence: holger.fink@hm.edu
}

Received: 16 July 2020; Accepted: 23 September 2020; Published: 29 September 2020

\begin{abstract}
From 2014 to 2018, issuers of retail structured products in Germany established and calculated the Issuer Estimated Value (IEV), a fair value designed to offer more transparency for retail investors. By reporting the IEV in the product information sheet, banks implicitly make a statement on their expected gross margin and, as one of the first papers, we provide an empirical study of the fairness of these disclosed figures. On a sample of discount and capped bonus certificates, we find that reported issuer margins can be verified using standard option pricing models and we illustrate that hedging costs take on an important role for structured product valuation. Consequently, the answer to the raised question in the title seems to be an (initial) 'yes' for our chosen product sample. Even though in 2018 the IEV calculations have been replaced by similar margin and cost statements due to the newly introduced Packaged Retail and Insurance-based Investment Products Regulation, this finding might still be a good guide for future research.
\end{abstract}

Keywords: issuer estimated value; fair value; retail structured products; discount certificates; bonus certificates

\section{Introduction}

Retail structured products are flexible investment instruments which give retail investors the opportunity to get access to customized payoff profiles in a simple way. Serving as an alternative for direct investments, retail structured products are bearer bonds issued by financial institutions typically packaging derivatives that create these special risk profiles. In Germany alone, one of the largest markets for retail structured products in the world, the current outstanding market volume amounts to around EUR 67 billion (67.3 billion Euros in Q2 2020, Deutscher Derivate Verband (2016) [1].). Trading of the products is either possible OTC, that is, directly with the issuer, or through a retail exchange such as EUWAX or Börse Frankfurt. In most cases, the provider of liquidity is the issuing institution itself which typically commits to operate as a market maker until maturity. Together with short selling restrictions, this however potentially offers a significant profit opportunity for the issuer.

While early academic papers, such as Reference [2] or Reference [3], focus on the US, there also exists a meaningful literature concerning the German market. In the following, we briefly review studies regarding the more conservative investment certificates leaving high risk structured products out (on these, for instance, see References [4-8]). The first extensive empirical analysis of issuer margins is carried out by Reference [9] who investigate 906 discount certificates and reverse convertibles on DAX and NEMAX stocks traded in November 2001. Using a replication strategy with suitable EUREX 
options, the authors find reverse convertibles on DAX (NEMAX) stocks to be priced $3.04 \%(3.89 \%)$ above their theoretical values, while prices of discount certificates presumably include an even larger issuer margin of $4.20 \%(10.04 \%)$ on average. Besides these results, Reference [9] find evidence for their order-flow hypothesis, which postulates that products are overpriced after issuance when most investors buy, and closer to the fair value when the number of certificates bought and sold is in equilibrium.

Later on, Reference [10] showed support for their life-cycle hypothesis which claims that issuer margins are earned continuously over the products' lifetimes, and thus, the overpricing should be higher for certificates with a longer time-to-maturity. Analyzing 2566 equity-linked structured products on the DAX and its constituents available on 10 October 2002, the authors apply the standard option pricing model of Reference [11] for the embedded plain vanilla and barrier options. Their results indicate that prices of DAX structured products lie on average $2.13 \%$ above their model value at issuance, while they are $0.11 \%$ lower in the secondary market. To find indication for declining margins as maturity approaches, Reference [10] regress the relative price deviations on the products' remaining lifetimes showing statistical significance.

Reference [12] is the first to address the influence of issuer's credit risk by comparing different models for the pricing of discount certificates-the (default-free) [11] setup, the Reference [13] approach assuming independence between the market and the issuer's credit quality, and finally a structural model which allows for correlation effects between the two sources of risk. Given a typically negative correlation between the issuer's credit risk and market returns, it turns out that margins calculated by the Reference [13] framework are strictly larger than those resulting from the structural model. Assuming the latter to be the more realistic setup, Reference [12] come to the conclusion that Deutsche Bank prices with the lowest issuer margins $(0.67 \%)$, followed by UBS $(0.84 \%)$, Commerzbank $(0.91 \%)$, BNP Paribas (1.29\%) and Société Générale (2.27\%).

In a more recent study, Reference [14] analyzes the order-flow hypothesis for a sample of discount certificates issued on the DAX index between November 2006 and December 2007. Using a Black-Scholes-type implied volatility model adjusted for credit risk, the author finds that margins have decreased to an overall average of $0.42 \%$. As an explanation for these seemingly surprising findings, Reference [14] refers to an increased volume and a more competitive market. For the more risky path-dependent bonus certificates, Reference [15] estimates average issuer margins between 1.98\% p.a. and 3.50\% p.a. after applying the stochastic volatility model of Reference [16] and incorporating credit risk with the independence approach of Reference [13]. Furthermore, the study in Reference [17] (The study in Reference [17] was supported by the Deutscher Derivate Verband (DDV), the issuers' lobby group in Germany.) considers a selected representative and a random sample, each consisting of 200 securities from different product categories, and the authors find a mean issuer margin of $0.36 \%$ p.a. and $0.46 \%$ p.a., respectively. In addition to credit risk, they include hedging costs in terms of a flat $2 \%$ barrier shift for products with barrier features which may explain how they obtain lower issuer margins than Reference [14].

In May 2014, resulting from discussions with regulators and the willingness to offer more transparency for retail clients, the Deutscher Derivate Verband (DDV) and the issuers in Germany established the so-called Issuer Estimated Value (IEV). The IEV is published in the product information sheet and should reflect a fair and market-consistent value of the certificate's payoffs, which are further adjusted for financing income as the investor acts as a capital provider for the issuer. Additionally, the IEV also accounts for hedging costs which are faced by the issuing banks. From there on, the issuers voluntarily commit to report the IEV of each investment certificate in its respective product information sheet which contains all relevant product features and a scenario analysis [18]. When banks disclose the IEV at the issue date, they also make an implicit statement on their gross margin which is the difference between the Issuer Estimated Value and the issue price typically expressed as percentage number. The gross issuer margin contains the bank's expected (To improve legibility, we often drop the word "expected." However, throughout the study, all gross issuer margins 
relate to expected profits which are not necessarily realized [17].) profits but also costs of distribution and selling. Figure 1 summarizes the definition of the Issuer Estimated Value and its price components as outlined by the DDV.

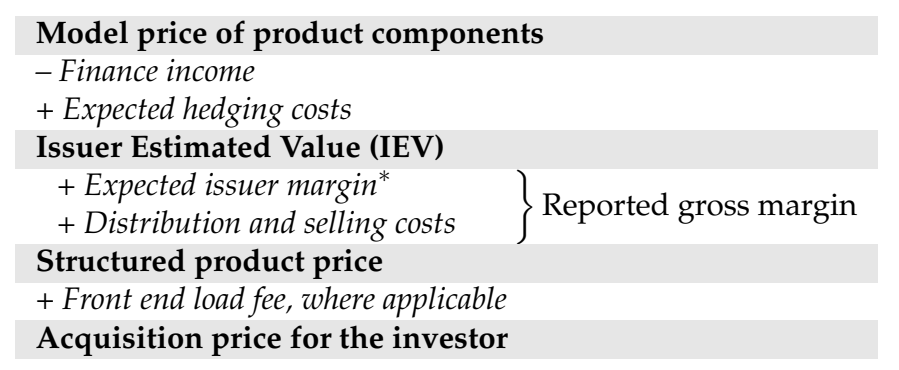

Figure 1. Price Components of a Retail Structured Product. This figure shows structured product price components according to Reference [18]. The asterisk $\left(^{*}\right)$ indicates that beyond the issuer's expected profits, the expected issuer margin covers operational costs incurred by product structuring, admission, market making and settlement.

Since then, to the best of our knowledge, there have only been a few studies who analyzed the fairness and market-consistency of the reported gross issuer margins-a gap we would like to continue closing with this paper. In particular, we focus on discount and capped bonus certificates, two important subclasses which account for about $11.7 \%$ of total outstanding volume and $29.7 \%$ of the total monthly trading volume in Germany (see Reference [1]). These two types of certificates due to their widespread availability and prominence have also been part of recent studies on diversification strategies for retail investors (see, e.g., Reference [19]). More complex products like autocallables are left for future research as there is still an ongoing academic debate which pricing models suit these specific payoffs best (see, e.g., Reference [20]).

On assessing the fairness of the reported gross margins, our present study should be considered together with Reference [21], who collected published IEVs of DAX certificates and stressed various difficulties when trying to validate the issuer's pricing models and with Reference [22] who carried out a similar analysis as the present paper, however focusing just on discount certificates. Although, in 2018 the IEV has been replaced by similar margin and cost information due to the newly introduced Packaged Retail and Insurance-based Investment Products Regulation, we believe that a study of the correctness and consistency of these values might still be a fruitful guide when considering these new statements. We will discuss this further in the conclusion.

To reduce pricing uncertainty arising from illiquid hedging instruments and different approaches of estimating dividend yields, we focus on the DAX performance index as the underlying security. For each product, we compare two numbers at the day of issuance: first, we derive the reported gross margin from the issue price and IEV, and, in a second step, compare this figure to a model-based gross margin computed from the first end-of-day ask price and an end-of-day model value. This procedure solves issues regarding the lack of information about the exact time of day when the IEV was derived. In total, we obtain a sample of 714 structured products issued between 30 September and 31 October 2015. In line with the recent studies of References $[14,15,17]$, we rely on two Black-Scholes-type pricing approaches using implied volatility surfaces and the stochastic volatility framework of Reference [16]. Default risk will be incorporated through the Reference [13] approach, but we will apply a flat adjustment of the individual issuer's CDS to account for credit/equity correlation. To incorporate hedging costs, we include a barrier shift and consider bid-ask spreads of traded options. Furthermore, we assess the robustness of our results with respect to different assumptions of such hedging adjustments and therefore mitigate pricing uncertainties ([21]).

The remainder of the chapter is organized as follows-Section 2 describes the selection procedure of discount and capped bonus certificates for the empirical analysis. Afterwards, we provide descriptive statistics of reported gross margins resulting from IEVs in the product information sheets. 
Then, Section 4 introduces the applied pricing frameworks explaining in detail how model parameters are calibrated and hedging costs applied, before we present the results of our empirical analysis in Section 5, and robustness tests in Section 6. The paper closes with a conclusion summarizing our main findings.

\section{Data Selection}

To assess the fairness and market-consistency of reported gross issuer margins, we focus on discount and capped bonus certificates which represent two important subclasses of retail structured products. In the following, we consider DAX index certificates issued between 30 September and 30 October 2015, a timeframe that can be characterized as a calm market period as illustrated in Figure 2. For data collection, we use OnVista, a website providing structured product selection tools and containing all exchange-listed products. Taking all securities in the mentioned product categories and the timeframe into account, we arrive at 1504 discount and 3208 capped bonus certificates in a first step.

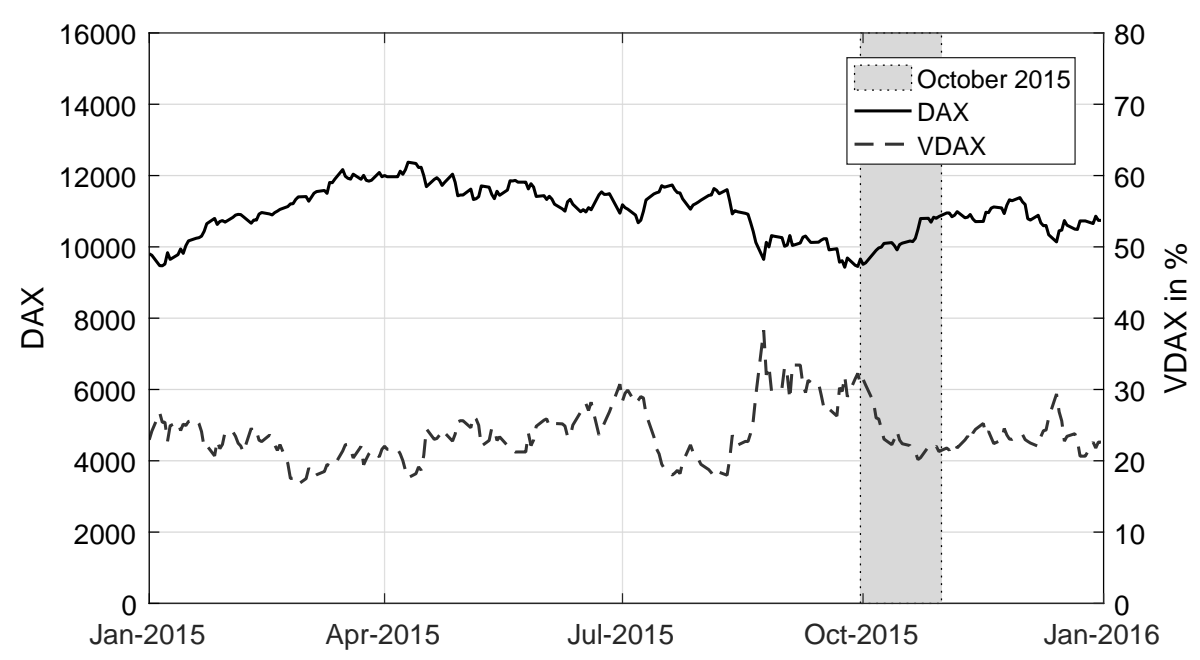

Figure 2. DAX and VDAX Index (January 2015-December 2015). Levels of the DAX and its volatility index VDAX are displayed during the period January 2015-December 2015. The grey-shaded area indicates the month October 2015 where the securities of our sample are issued.

To achieve more homogeneity of the certificates' characteristics and ensure the availability of actively traded derivatives at EUREX for model calibration, we only consider products with lifetimes larger than 3 and smaller than 24 months. We further filter by maturity and identify timeframes in which at least two issuers are present with more than five single products that have a (nearly) similar counterpart from another issuer. Additionally, we only consider products expiring on quarterly dates as they usually offer a more liquid hedging market. For discount certificates, these timeframes are June-August, October-November 2016, February-March and September 2017. And correspondingly, for capped bonus certificates, these periods are March, June, December 2016 and March 2017. Finally, this selection procedure yields a data set with 501 discount and 259 bonus certificates issued from eight different banks. Specifically, the data set contains discount certificates issued by Commerzbank $(N=144), \operatorname{HSBC}(N=85)$, Citigroup $(N=73)$, DZ Bank $(N=62)$, Vontobel $(N=55)$, Goldman Sachs $(N=20)$ and BNP Paribas $(N=17)$.

In the subsample of capped bonus certificates, we have securities from DZ Bank $(N=77)$, BNP Paribas $(N=58)$, Deutsche Bank $(N=49)$, Goldman Sachs $(N=18)$ and Vontobel $(N=11)$. Note that the 46 capped bonus certificates of HypoVereinsbank (HVB) have to be dropped from the final data set as HVB did not provide any product information sheets with Issuer Estimated Values during October 2015. Finally, closing bid and ask quotes are obtained from the EUWAX exchange for 
all 714 structured products at the respective day of issuance, 5:30 p.m. Frankfurt time. Issuer Estimated Values, product issue prices and dates are extracted from the product information sheets downloaded from each bank's webpage.

\section{Reported Gross Margins and Product Lifetimes}

In the following, we take reported Issuer Estimated Values from product information sheets and put them in a relation to issue prices to deduce the reported gross issuer margin for each product. To obtain a more balanced panel, we divide the reported gross margin by the time-to-maturity $T$ to obtain an annualized figure which is specifically defined as

$$
\text { Reported gross margin p.a. }{ }_{i}=\frac{1}{T_{i}}\left(1-\frac{\mathrm{IEV}_{i}}{{\text { Issue } \text { Price }_{i}}_{i}}\right) .
$$

Table 1 provides summary statistics of the reported annualized gross margins and product lifetimes for the overall data set $(N=714)$ and throughout this paper, only annualized gross margins are considered. In total, the reported gross margins are on average $0.61 \%$ p.a. and the mean time-to-maturity is 1.19 years.

Table 1. Reported Gross Margins and Product Lifetimes.

\begin{tabular}{|c|c|c|c|c|c|c|c|c|c|}
\hline \multirow[b]{2}{*}{ Issuer } & \multirow[b]{2}{*}{$\mathbf{N}$} & \multicolumn{4}{|c|}{ Reported Gross Margin in \% p.a. } & \multicolumn{4}{|c|}{ Time-to-Maturity in Years } \\
\hline & & Mean & Std. & Min. & Max. & Mean & Std. & Min. & Max. \\
\hline \multicolumn{10}{|c|}{ Panel A: Discount Certificates } \\
\hline BNP Paribas & 17 & 1.41 & 0.10 & 1.34 & 1.66 & 1.20 & 0.22 & 0.77 & 1.38 \\
\hline Citigroup & 73 & 0.68 & 0.12 & 0.31 & 0.82 & 1.12 & 0.14 & 0.73 & 1.44 \\
\hline Commerzbank & 144 & 0.05 & 0.01 & 0.04 & 0.08 & 1.31 & 0.17 & 1.12 & 1.45 \\
\hline Deutsche Bank & 45 & 0.11 & 0.23 & 0.02 & 0.81 & 1.38 & 0.22 & 0.69 & 1.46 \\
\hline DZ Bank & 62 & 0.01 & 0.00 & 0.00 & 0.02 & 1.57 & 0.48 & 1.02 & 2.02 \\
\hline Goldman Sachs & 20 & 0.73 & 0.03 & 0.69 & 0.76 & 0.78 & 0.22 & 0.67 & 1.45 \\
\hline HSBC & 85 & 0.18 & 0.04 & 0.04 & 0.27 & 1.20 & 0.40 & 0.72 & 1.99 \\
\hline Vontobel & 55 & 1.58 & 0.31 & 1.38 & 2.20 & 1.62 & 0.46 & 0.83 & 1.98 \\
\hline Overall & 501 & 0.40 & 0.54 & 0.00 & 2.20 & 1.31 & 0.37 & 0.67 & 2.02 \\
\hline \multicolumn{10}{|c|}{ Panel B: Capped Bonus Certificates } \\
\hline BNP Paribas & 58 & 2.73 & 0.52 & 2.28 & 3.51 & 0.88 & 0.35 & 0.42 & 1.19 \\
\hline Deutsche Bank & 49 & 0.42 & 0.20 & 0.02 & 0.68 & 0.81 & 0.35 & 0.46 & 1.22 \\
\hline DZ Bank & 77 & 0.20 & 0.01 & 0.20 & 0.22 & 0.92 & 0.35 & 0.39 & 1.49 \\
\hline Goldman Sachs & 18 & 1.28 & 0.02 & 1.27 & 1.31 & 1.16 & 0.36 & 0.45 & 1.47 \\
\hline Vontobel & 11 & 1.47 & 0.08 & 1.39 & 1.57 & 1.01 & 0.54 & 0.39 & 1.48 \\
\hline Overall & 213 & 1.10 & 1.10 & 0.02 & 3.51 & 0.91 & 0.37 & 0.39 & 1.49 \\
\hline
\end{tabular}

Entries report descriptive statistics of reported gross margins (annualized, in \%) for discount and capped bonus certificates across the issuing institutions. Furthermore, the number of observations in each subsample and the respective time-to-maturities are stated.

In the subsample of discount certificates, the mean reported gross margin at issue date is $0.40 \%$ p.a. and securities expire on average 1.31 years after issuance. These reported issuer margins are of the same magnitude as those obtained before by the earlier academic papers, for example, References [14,17], who derive $0.42 \%(0.39 \%)$ p.a. for discount certificates, respectively. Although any comparison across banks should be treated with care as the products' characteristics may deviate, Vontobel seems to offer discount certificates with the highest gross margins ranging from $1.38 \%$ p.a. up to $2.20 \%$ p.a. Furthermore, DZ Bank reports the lowest gross margin with at most $0.02 \%$ p.a. of the product price with an average time-to-maturity of 1.57 years.

For the subsample of 213 capped bonus certificates, reported gross issuer margins range from $0.02 \%$ p.a. to $3.51 \%$ p.a. with an average of $1.10 \%$ p.a. and 0.91 years mean 
time-to-maturity-notably shorter than discount certificates. The reported margins are in accordance with the magnitude derived by Reference [17] who obtain a result of $0.90 \%$ p.a. for capped bonus certificates at the date of issuance. In our sample, BNP Paribas reports highest gross margins ranging from $2.28 \%$ p.a. to $3.51 \%$ p.a., while DZ Bank states the lowest charges with $0.20 \%$ p.a. on average. Overall, for both discount and capped bonus certificates, we find a notable heterogeneity of reported gross margins across issuers even after ensuring that the products have similar characteristics. Nevertheless, margin discrepancies across issuers can also be explained by different interpretations of the IEV standard which does not state explicit guidelines on the pricing methods and specification of hedging costs. In particular, the fairness code [18] mentions trading costs and bid-ask spreads as potential cost of hedging. As earlier papers do not account for any of these expenses, we incorporate hedging costs in our pricing methodology in terms of the options' bid-ask spread which issuers are facing when hedging the derivative components. The detailed procedure is explained in the following.

\section{Methodology}

\subsection{Payoff Replication}

Payoffs of a discount certificate $D_{i}$ can be replicated by a long position in a zero-strike call and a short position in a European call option with strike $K_{i}$ and maturity $T_{i}$ :

$$
D_{i}=C\left(0, T_{i}\right)-C\left(K_{i}, T_{i}\right) .
$$

For a capped bonus certificate $C B_{j}$, the replication scheme consists of a long position in a zero-strike call, a long position in a down-and-out put with respect to a barrier $H_{j}$ and strike $K_{j}$, and a short European call with the same strike $K_{j}$. Same as for discount certificates, all options included have identical maturities $T_{j}$ :

$$
C B_{j}=C\left(0, T_{j}\right)+P^{D O}\left(K_{j}, H_{j}, T_{j}\right)-C\left(K_{j}, T_{j}\right) .
$$

The strike $K_{j}$ is commonly called the bonus level and the respective payoff sketches are presented in Figure 3. For valuation of these derivative components, possible choices for the option pricing models are manifold. To reduce uncertainty arising from the model choice, we implement three entirely different approaches, namely the commonly used [16] stochastic volatility model, the Reference [23] implied volatility model, which we refer to as the Practitioner Black-Scholes (PBS) model, and the non-parametric Nadaraya-Watson approach [24,25].
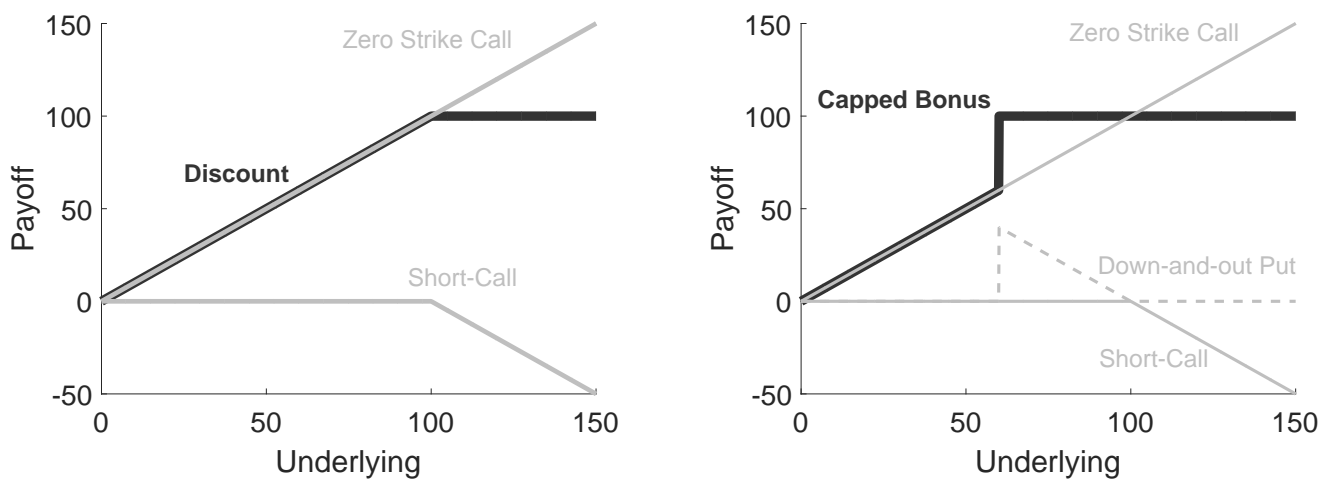

Figure 3. Discount and Capped Bonus Certificates' Payoff and Replication. Illustration of the payoff function and replication scheme for discount (right) and capped bonus certificates (left). Here, the cap level is set to 100 and the barrier to 60 as an example. 


\subsection{Heston Model}

For the Reference [16] stochastic volatility model, we assume that underlying value and variance are determined by the following dynamics under the risk-neutral measure:

$$
\begin{aligned}
\frac{\mathrm{d} S_{t}}{S_{t}} & =r \mathrm{~d} t+\sqrt{v_{t}} \mathrm{~d} B_{t}^{1}, & & S_{0}>0, \\
\mathrm{~d} v_{t} & =\kappa\left(\theta-v_{t}\right) \mathrm{d} t+\sigma \sqrt{v_{t}} \mathrm{~d} B_{t}^{2}, & & v_{0} \geq 0 .
\end{aligned}
$$

Here, $S_{t}$ denotes the underlying asset value at time $t, r$ equals the continuously compounded risk-free rate and $\sqrt{v_{t}}$ denotes a stochastic volatility process. The time-varying variance $v_{t}$ is driven by a Cox-Ingersoll-Ross [26] (CIR) process with reversal speed rate $\kappa>0$, long run variance $\theta \geq 0$ and the volatility of variance parameter $\sigma>0$. The underlying asset value and variance process is initialized with $S_{0}>0$ and $v_{0} \geq 0$, respectively. Furthermore, $\left(B_{t}^{1}\right)_{t \geq 0}$ and $\left(B_{t}^{2}\right)_{t \geq 0}$ are two Brownian motions correlated with $\rho \in[-1,1]$. For numerical robustness, we use the call price formula presented by Reference [27] in its most common variant which can be expressed as

$$
C(K, T)=S_{0}-\frac{1}{\pi} \sqrt{S_{0} K} e^{-r T / 2} \int_{0}^{\infty} \operatorname{Re}\left[e^{i u m} \varphi\left(u-\frac{i}{2}\right)\right] \frac{\mathrm{d} u}{u^{2}+0.25} .
$$

In this expression, $\varphi$ equals the characteristic function of log asset returns (see, for the "Heston Trap" version, Reference [28]), $K$ denotes the strike price and $m=\log \left(\frac{S}{K}\right)+r T$ is a measure of option moneyness. In the following, we use a 100-points Gauss-Laguerre quadrature which ensures a high numerical accuracy of the computed integral in the call price Formula (6).

\subsection{Pbs Model}

Reference [23] presents an implied volatility model based on deterministic functions. In this approach, the Black-Scholes implied volatility $\sigma_{B S}$ is directly determined by a polynomial of option characteristics. In particular, we use the moneyness and time-to-expiry of the respective option as explanatory variables:

$$
\sigma_{B S}(M, T)=a_{0}+a_{1} M+a_{2} M^{2}+a_{3} T+a_{4} T^{2}+a_{5} T M+\varepsilon .
$$

Here, $a$ is a vector of regression coefficients, $T$ denotes the option's time-to-maturity, $M=\frac{S_{0}}{K}$ represents the option's simple moneyness and $\varepsilon$ equals a standard normally distributed error term. The linear form of Equation (7) allows to obtain closed form estimates for the coefficients using standard least squares methods. If regression coefficients are available, options can be priced by plugging the respective option characteristics into Equation (7) to obtain a volatility parameter $\sigma_{B S}$. This estimate can subsequently be used in the standard Black-Scholes formulas.

\subsection{Nadaraya-Watson Smoothing}

Both the Heston and PBS model are typically used to provide a global fit to discrete implied volatility observations. However, it is also common practice to use non-parametric methods, such a spline interpolation or kernel regressions which provide a local fit to the option data. Following References [24,25], we additionally use a non-parametric Nadaraya-Watson (NW) estimator to obtain a smooth volatility surface:

$$
\sigma_{B S}(M, T)=\frac{\sum_{k=1}^{N_{t}} \sigma_{B S}\left(M_{k}, T_{k}\right) \phi\left(M-M_{k}, T-T_{k}\right)}{\sum_{k=1}^{N_{t}} \phi\left(M-M_{k}, T-T_{k}\right)},
$$


where

$$
\phi(x, y)=\frac{1}{2 \pi} \exp \left(-\frac{x^{2}}{2 h_{x}}\right) \exp \left(-\frac{y^{2}}{2 h_{y}}\right)
$$

is a bivariate Gaussian kernel. In this formula, $T_{k}$ and $M_{k}=\frac{S_{0}}{K_{k}}$ denote the $k$-th option's time-to-maturity and simple moneyness that are used for calibration. The bandwidth parameters $h_{x}, h_{y}$ control for the degree of smoothness in the time and moneyness dimension of the volatility surface and have to be specified separately. Using a "leave-one-out" cross-validation procedure, we set the bandwidth for each day and maturity date to account for the different sparseness of option data. Further, we determine the kernel bandwidth in the time dimension by the minimum distance to the next maturity date. For illustration, some resulting volatility surfaces are shown in Figure A1 in the appendix.

\subsection{Pricing Down-and-Out Options}

Pricing path-dependent barrier options imposes more technical difficulties than the valuation of their European-style counterparts. For the Heston model, we price the down-and-out put option using Monte Carlo simulations. To prevent numerical instabilities of the variance process near zero, we use the Reference [29] moment matched log-normal approximation scheme to simulate trajectories of the underlying. As the simulation is time-consuming, we restrict the stock path simulation to one-minute (For robustness, we also used ten and one second simulation time intervals for several securities, but the resulting prices were not notably affected.) time intervals. The mean payoff resulting from $1,000,000$ sample paths is discounted to obtain the fair value of the embedded down-and-out put

$$
P^{D O}(K, H, T)=\exp (-r T)\left(\frac{1}{1,000,000} \sum_{s=1}^{1,000,000}\left(K-S_{T}^{S}\right)^{+} \mathbb{I}_{\left\{\min _{t \in[0, T]} S_{t}^{s}>H\right\}}\right) .
$$

According to Reference [30], we additionally use the value of a plain-vanilla put option and the drift rate as control variates for an effective variance reduction of the Monte-Carlo estimate. Control variates are also useful for the correction of a potentially occurring bias resulting from the simulation scheme.

For the Black-Scholes model, Reference [31] presents a closed-form solution for this option type exploiting the barrier option's in-out parity. In detail, this means that prices of a down-and-out put option can be expressed as a difference between the value of a plain vanilla put and the respective down-and-in option

$$
P^{D O}(K, H, T)=P(K, T)-P^{D I}(K, H, T),
$$

where

$$
\begin{aligned}
P^{D I}(K, H, T)= & -S_{0} \mathcal{N}\left(-x_{1}\right)+K \exp (-r T) \mathcal{N}\left(-x_{1}+\sigma_{B S} \sqrt{T}\right) \\
& +S_{0}\left(\frac{H}{S_{0}}\right)^{2 \lambda}\left(\mathcal{N}(y)-\mathcal{N}\left(y_{1}\right)\right) \\
& -K \exp (-r T)\left(\frac{H}{S_{0}}\right)^{2 \lambda-2}\left(\mathcal{N}\left(y-\sigma_{B S} \sqrt{T_{i}}\right)-\mathcal{N}\left(y_{1}-\sigma_{B S} \sqrt{T}\right)\right)
\end{aligned}
$$

and

$$
\begin{array}{lrl}
\lambda=\frac{r+\frac{\sigma_{B S}^{2}}{2}}{\sigma_{B S}^{2}}, & y=\frac{\log \left(\frac{H^{2}}{S_{0} K}\right)}{\sigma_{B S} \sqrt{T}}+\lambda \sigma_{B S} \sqrt{T}, \\
x_{1}=\frac{\log \left(\frac{S_{0}}{H}\right)}{\sigma_{B S} \sqrt{T}}+\lambda \sigma_{B S} \sqrt{T}, & y_{1}=\frac{\log \left(\frac{H}{S_{0}}\right)}{\sigma_{B S} \sqrt{T}}+\lambda \sigma_{B S} \sqrt{T} .
\end{array}
$$


For the derivation of this formula, it is assumed that the underlying asset $S_{t}$ is observed continuously and that the barrier $H$ can be breached at any time until maturity. Deutsche Börse derives the DAX index only every second, applying the above-mentioned barrier price formulas, however, potentially introduces a small bias. To account for this discrepancy, Reference [32] provides a correction for the closed-form expressions of barrier option prices in the Black-Scholes framework. With $T / n$ relating to the time of one second, a corrected closed-form solution can be obtained by a barrier adjustment of $H \cdot \exp \left(-0.5826 \sigma_{B S} \sqrt{T / n}\right)$.

\subsection{Model Calibration and CDS}

For calibration of our models, we use daily closing prices of the DAX index and closing bid/ask quotes of European-style DAX index options from EUREX, which can be accessed by Thomson Reuters Datastream. To begin with, we apply standard exclusion criteria to obtain option quotes that are reliable and as close as possible to prices of actual trades. First, we drop all option quotes where either the bid or the ask price is not available or does not satisfy standard no-arbitrage conditions. Second, we only consider actively traded options with more than three months or less than two years time-to-expiration, a range capturing the minimum and maximum time-to-maturity of our certificates. Third, we drop all in-the-money option quotes, and out-of-the-money quotes that do not satisfy the moneyness criterion $\left|S_{0} / K-1\right| \leq 0.4 \sqrt{T}$. The reason for this is that prices of in-the-money options are mainly driven by their intrinsic values and far out-of-the-money derivatives are typically traded infrequently.

As the characteristics of the embedded options may differ from those traded on the market, we sequentially calibrate the Heston and PBS model at each date of issuance to the option data. For this purpose, we obtain Black-Scholes implied volatilities from mid option prices $\mathcal{P}_{\text {Market }}$ of the remaining call and put options and match with implied volatilities computed by the Heston or PBS model prices $\mathcal{P}_{\text {Model }}$. Finally, we choose model parameters in a way such that the root mean squared errors of implied volatility (IVRMSE) are minimized,

$$
\text { IVRMSE }=\sqrt{\frac{1}{N_{t}} \sum_{k=1}^{N_{t}}\left(\sigma_{B S}\left(\mathcal{P}_{\text {Model }, k}\right)-\sigma_{B S}\left(\mathcal{P}_{\text {Market }, k}\right)\right)^{2}},
$$

where $N_{t}$ denotes the number of option quotes at day $t$. As the Nadaraya-Watson approach is non-parametric, it is not calibrated using the objective function (14), but rather the cross-validation procedure explained in Section 4.4 is applied. To approximate the risk-free interest rate, we use maturity-matched Euro overnight swap rates which are available for a large range of different maturities up to 10 years. To obtain the risk-free rate corresponding to the certificate's maturity, we use simple linear interpolation of the two rates straddling the date of expiry. Furthermore, credit spreads are obtained daily from senior unsecured one-year CDS of each issuer. As no CDS or bond yields are available for Vontobel, we approximate these values through an average of CDS spreads from UBS and Credit Suisse, which have a similar (In October 2015, the Moody's long term issuer rating is A3 for Vontobel Holding AG, A1 for UBS and Baa3 for Credit Suisse. According to Moody's rating scale, A3 is almost right in between A1 and Baa3.) Moody's long term issuer rating and operate on the same market.

Figure 4 shows Heston and PBS model parameters and the IVRMSE in-sample fit obtained from daily calibration during the period October 2015. The sequentially calibrated Heston and PBS model parameters are fairly stable over time, except the spot variance parameter which decreases noticeably after the first days. A less pronounced decline can also be observed for the PBS intercept $a_{0}$, however the spot variance is also effected by the moneyness coefficients $a_{1}$ and $a_{2}$. The overall in-sample fit of both the PBS and Heston model is in a typical range shown by other studies, for example, Reference [33]. With a value of 0.0041, the average PBS in-sample fit of option data is slightly better than of the Heston model with 0.0050 . 

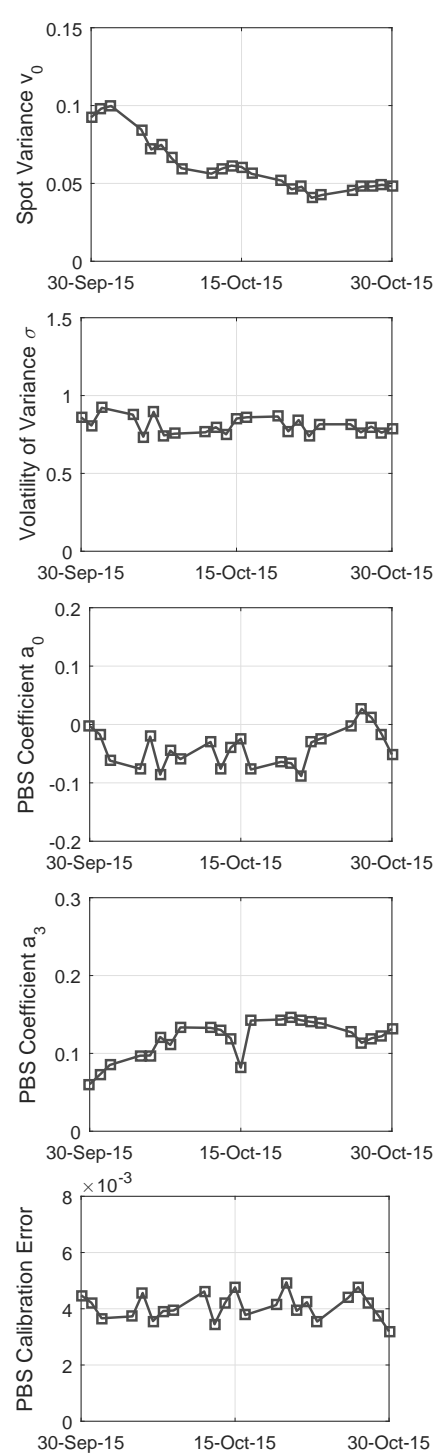
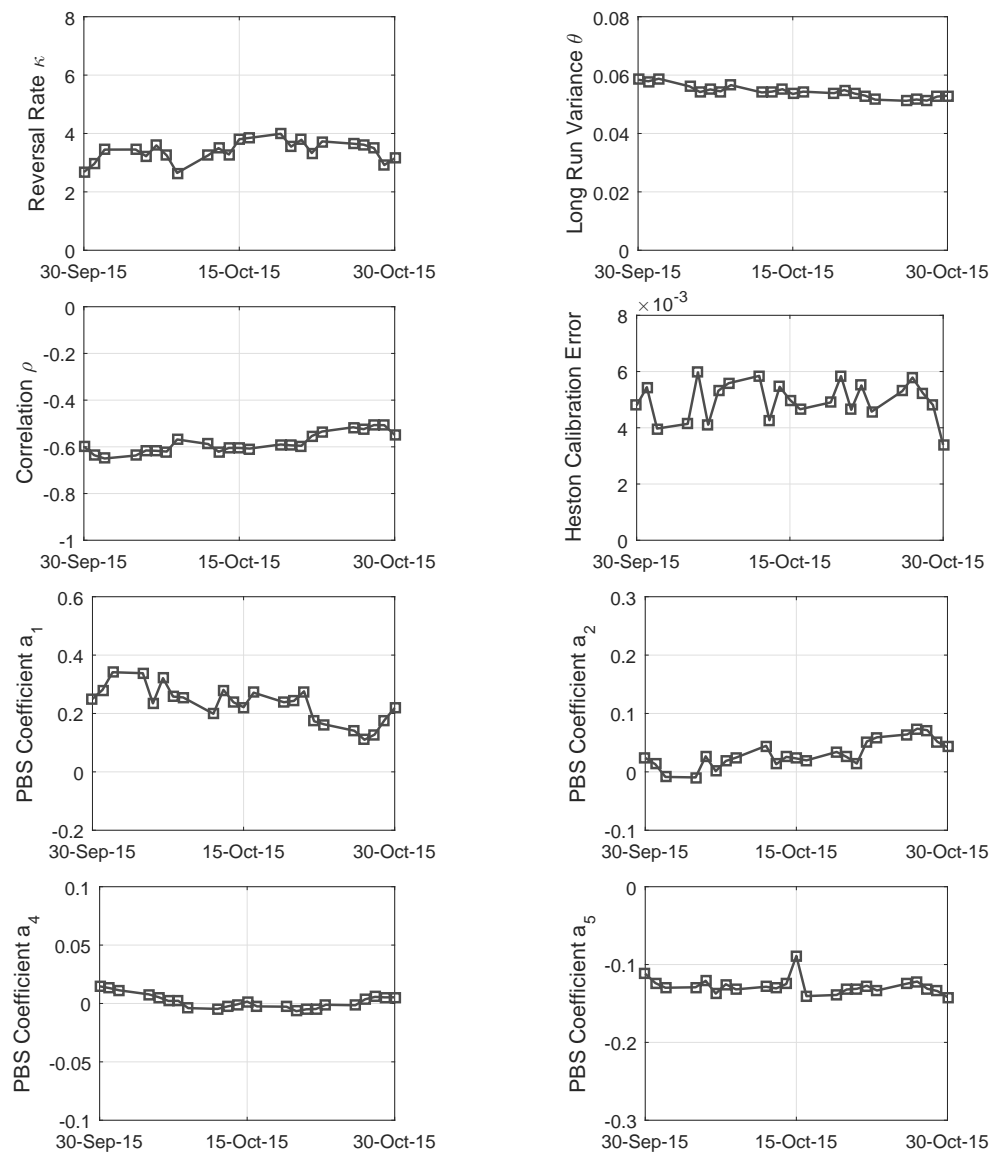

Figure 4. Calibrated Heston and Practitioner Black-Scholes (PBS) Model Parameters, and In-Sample Fit. Model parameters and the root mean squared errors of implied volatility (IVRMSE) in-sample fit are reported for the Heston and PBS model. Each model is sequentially calibrated to end-of-day DAX index option quotes between 30 September 2015 and 30 October 2015.

\subsection{Default Risk and Hedging Costs}

Following the definition of the Issuer Estimated Value, the raw model price obtained by the sum of the individual option components has to be adjusted for credit risk and hedging costs. Assuming independence of the bank's default risk and the underlying of the derivative, Reference [13] propose to discount the default-free model price with the issuer's credit spread $s_{l}$. However, as pointed out by Reference [12], neglecting the correlation between market and credit risk may lead to biased results. From a practical perspective, this relevance can be illustrated as follows-for products that profit from rising markets (e.g., discount and capped bonus certificates), a dropping underlying value usually leads to investors selling off their securities early. However, in such a downside market, the bank's funding costs reflected in their CDS rates typically rise. In total, when the issuer actually needs the additional funding provided by structured products, he might face larger buybacks-a risk the issuer does not face with usual bonds. Considering the relevance of correlation as illustrated by Reference [12], we reduce the credit spreads $s_{l}$ by 20 basis points. However, if one is interested 
in results without this adjustment, the 20 basis points p.a. can easily be added to the derived gross margins in Sections 5 and 6.

Also, occurring hedging costs have to be reflected in the fair value. Hedging a discount and a capped bonus certificate requires the issuer to short a call option at the EUREX exchange. By selling and potentially closing the position at later point in time, the issuer has to pay the bid-ask spread. To account for these trading costs in the calculation of the model-based fair value, we consider the median call option bid-ask spread expressed in terms implied volatility as a proxy. We derive this value from option data of the prior month September 2015 and reduce our respective pricing volatilities for the short calls by $0.62 \%$ per year in the following. For pricing of capped bonus certificates, we additionally follow the approach of Reference [17] and adjust the barrier with a flat barrier shift of $2 \%$ to account for gap risk (For a more technical treatment of gap and jump risk, see Reference [34].). In particular, this means that the embedded down-and-out put option is evaluated at a $2 \%$ smaller barrier, for example, to reflect jump risk in the underlying.

Finally, fair values of discount certificates $F V^{D}$ and capped bonus certificates $F V^{C B}$ of issuer $l$ are derived for each model (i.e., Heston, PBS and Nadaraya-Watson) from

$$
\begin{aligned}
F V_{i}^{D} & =e^{-\left(s_{l}-0.002\right) T_{i}}\left(C\left(0, T_{i}\right)-C^{*}\left(K_{i}, T_{i}\right)\right), \\
F V_{j}^{C B} & =e^{-\left(s_{l}-0.002\right) T_{j}}\left(C\left(0, T_{j}\right)+P^{D O}\left(K_{j}, H_{j}^{*}, T_{j}\right)-C^{*}\left(K_{j}, T_{j}\right)\right),
\end{aligned}
$$

where $C^{*}$ is the respective call price with reduced implied volatility and $P^{D O}$ is the value of the down-and-out put evaluated at a $2 \%$ lower barrier $H^{*}$, that is, $H^{*}=0.98 \cdot H$.

\subsection{Model-Based Gross Margins}

For ease of comparison to the reported gross margins, we derive the model-based counterparts as follows: first, the fair values $F V^{D}$ and $F V^{C B}$ are derived for each option pricing approach and are then compared to the observed 5:30 p.m. ask prices on their respective issue dates in a second step. Thus, the model-based annualized gross margin of a discount and a capped bonus certificate is defined as

$$
\begin{aligned}
\text { Model-based gross margin p.a. }{ }_{i}^{D} & =\frac{1}{T_{i}}\left(1-\frac{F V_{i}^{D}}{\text { Ask Price }_{i}^{\text {close }}}\right), \\
\text { Model-based gross margin p.a. }{ }_{j}^{C B} & =\frac{1}{T_{j}}\left(1-\frac{F V_{j}^{C B}}{\text { Ask Price }_{j}^{\text {close }}}\right) .
\end{aligned}
$$

\section{Results}

In the following, we compare reported gross issuer margins from Section 3 with their Heston, PBS and Nadaraya-Watson model-based counterparts from Section 4. The numbers are calculated for each certificate once at the day of issuance.

\subsection{Comparison across Issuers}

Regarding discount certificates, Table 2 shows summary statistics of gross margins derived from the Heston, PBS and Nadaraya-Watson approach which can be compared to the reported values. Same as in Sections 2 and 3, we split up the data to different issuer subsamples. As a comparison of different mean values does not allow for an analysis of individual margin differences, we additionally compute the deviation between the reported margins and the respective model-based counterparts. To measure the scattering, we derive mean absolute errors (MAE) and root mean squared errors (RMSE), as well as minimum and maximum of this difference reported in the columns "Reported-Model". 
Table 2. Result Summary Statistics for Discount Certificates.

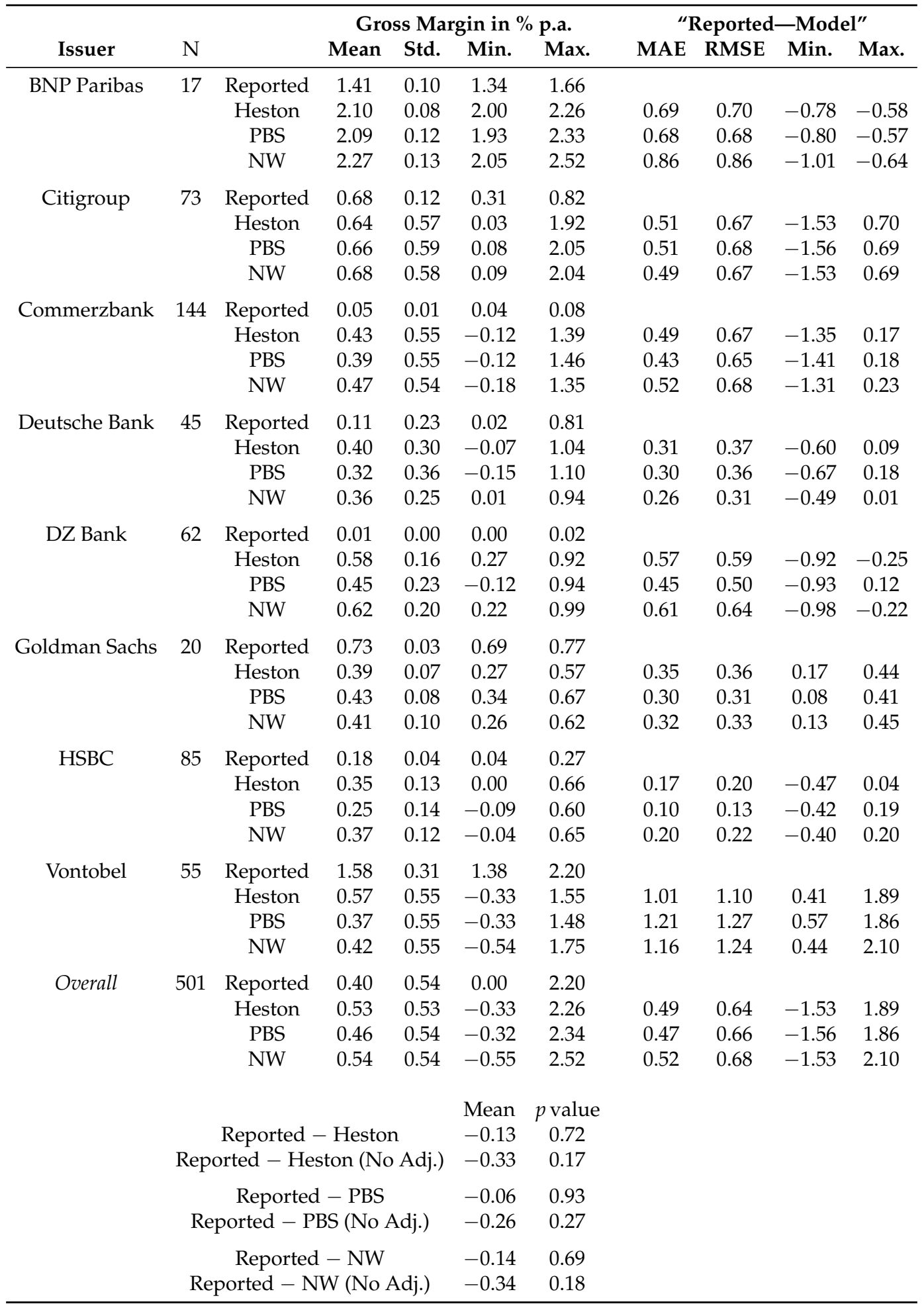

The table shows summary statistics of reported and model-based annualized gross margins for discount certificates. "Reported - Model" is defined as the reported gross margin in \% p.a. minus model-based gross margin in \% p.a. Assuming independence of the pricing errors across issuers and pricing dates, we perform a weighted paired $t$-test to investigate significance of the overall deviation of reported and model-based gross margins. In the bottom line, we also test for significance of the pricing deviations if the correlation adjustment from Section 4.7 is omitted.

Overall, our results seem to be considerably robust with respect to the particular choice of the option pricing model. All three considered approaches, Heston, PBS and Nadaraya-Watson 
imply similar results for the European-style discount certificates. In terms of the MAE and RMSE, differences between reported and model-based margins are low across all issuers, we only observe for Vontobel a one percentage point higher reported issuer margin than it was derived. In fact, when only considering averages, we have mean reported gross margins of $0.40 \%$ p.a. compared to Heston ( $0.53 \%$ p.a.), PBS $(0.46 \%$ p.a.) and Nadaraya-Watson ( $0.54 \%$ p.a.). To test for statistical significance of the deviations, we assume independence of the pricing deviations across issuers and issue dates and perform a weighted paired $t$-test. Indicated by $p$-values above 0.1 , we do not find significant discrepancies of the reported and model-based gross margins overall even if the correlation adjustment of 20 basis points from Section 4.7 is omitted. Possibilities to test for systematic deviations on the issuer level are limited as we do not have sufficient variation (For an overview on the valuation dates of discount and capped bonus certificates, see Table A1 in the appendix.) of distinct pricing dates, and as we might have possibly wrong assumptions on funding costs of an individual issuer which impact all model-based gross margins at the same time. In total, all pricing approaches indicate that the average gross issuer margins are smaller than $1 \%$ which is also in accordance with the results of References [14,17].

Considering individual issuers, we find that although Vontobel reports the highest gross margins on average, our model-based results are $1 \%$ lower and well in the range of those from the market competitors. This result is also reflected in MAEs and RMSEs which are twice as high as for other issuers. These findings can potentially be explained by the fact that Vontobel's own treasury is funding these certificates higher than by our CDS approximation (see Section 4). Whereas Citigroup, Goldman Sachs and HSBC state margins roughly in line with those we have calculated, we find BNP Paribas, Commerzbank, Deutsche Bank, and DZ Bank state lower average margins compared to results based on the Heston, PBS and the Nadaraya-Watson approach.

For the subsample of capped bonus certificates, Table 3 presents summary statistics of the model-based gross margins which can be compared to the issuer reported figures. For gross margins based on the Heston model, the differences are in a reasonable range and may fall under the present pricing and calibration uncertainty. This is also reflected by MAE and RMSE being equally low across most issuers. In particular, the mean reported gross margin (1.10\% p.a.) is close to the average based on the Heston model ( $1.35 \%$ p.a.). Same as for the discount certificates, we also perform a weighted paired $t$-test and find the differences to be insignificant. Nevertheless, if we do not include the correlation adjustment of 20 basis points, the gross margin deviation increases by this amount and becomes significant at a $5 \%$ level as indicated by $\left({ }^{* *}\right)$.

According to the Heston model and similar to the analysis of discount certificates, BNP Paribas' structured products contain the largest average margin (2.67\% p.a.) which is in accordance with the mean reported value (2.73\% p.a.). Average gross margin of capped bonus certificates issued by Deutsche and DZ Bank ( $0.84 \%$ p.a. and $0.62 \%$ p.a.) are notably above the reported values $(0.28 \%$ p.a. and $0.19 \%$ p.a.). Based on the Heston model, we derive an average margin of $1.44 \%$ p.a. for Goldman Sachs certificates which is in the range of the reported average gross margin of $1.28 \%$ p.a. For Vontobel, we derive $1.60 \%$ p.a. for their capped bonus certificates compared to reported value of $1.47 \%$ p.a.

Not surprisingly, we obtain implausible results using the PBS and Nadaraya-Watson setup but we report these for the sake of completeness. This can be explained by the inability of the Gaussian Black-Scholes model to price the embedded barrier option of a capped bonus certificates adequately. Both approaches, PBS and Nadaraya-Watson, only provide one volatility estimate for a certain strike/expiry date combination, which does not account for the set of marginal return distributions during the option's lifetime. Even if in-sample fit of all models is good for plain-vanilla options, there might be remarkable price differences for exotic options [35]. This weakness of the PBS and Nadaraya-Watson approach typically leads to an overpricing of the path-dependent down-and-out put. As well-known by academics and practitioners, the stochastic volatility of the Heston model is a far more adequate choice for pricing exotics, such as barrier options. Due to this fact, we also refrain from reporting any statistics on significance to save space in Table 3. 
Table 3. Result Summary Statistics for Capped Bonus Certificates.

\begin{tabular}{|c|c|c|c|c|c|c|c|c|c|c|}
\hline \multirow{2}{*}{ Issuer } & \multirow[b]{2}{*}{$\mathbf{N}$} & & \multicolumn{4}{|c|}{ Gross Margin in \% p.a. } & \multicolumn{4}{|c|}{ “Reported - Model" } \\
\hline & & & Mean & Std. & Min. & Max. & MAE & RMSE & Min. & Max. \\
\hline \multirow[t]{4}{*}{ BNP Paribas } & 58 & Reported & 2.73 & 0.52 & 2.29 & 3.51 & & & & \\
\hline & & Heston & 2.67 & 0.35 & 2.10 & 3.25 & 0.22 & 0.24 & -0.44 & 0.43 \\
\hline & & PBS & -0.30 & 1.26 & -3.46 & 2.10 & 3.03 & 3.39 & 0.19 & 6.93 \\
\hline & & NW & -0.31 & 1.27 & -3.62 & 2.16 & 3.04 & 3.42 & 0.13 & 7.09 \\
\hline \multirow[t]{4}{*}{ Deutsche Bank } & 49 & Reported & 0.42 & 0.20 & 0.02 & 0.68 & & & & \\
\hline & & Heston & 0.84 & 0.16 & 0.32 & 1.12 & 0.42 & 0.47 & -0.90 & -0.21 \\
\hline & & PBS & -2.44 & 2.31 & -9.03 & 0.28 & 2.86 & 3.72 & -0.02 & 9.60 \\
\hline & & NW & -2.48 & 2.40 & -9.12 & 0.44 & 2.92 & 3.82 & -0.18 & 9.69 \\
\hline \multirow[t]{4}{*}{ DZ Bank } & 77 & Reported & 0.20 & 0.01 & 0.20 & 0.22 & & & & \\
\hline & & Heston & 0.62 & 0.21 & 0.12 & 1.06 & 0.42 & 0.46 & -0.86 & 0.08 \\
\hline & & PBS & -2.27 & 1.84 & -8.89 & 0.23 & 2.47 & 3.08 & -0.03 & 9.10 \\
\hline & & NW & -2.28 & 1.97 & -9.42 & 0.23 & 2.48 & 3.16 & -0.02 & 9.63 \\
\hline \multirow[t]{4}{*}{ Goldman Sachs } & 18 & Reported & 1.28 & 0.02 & 1.27 & 1.31 & & & & \\
\hline & & Heston & 1.44 & 0.30 & 0.80 & 1.99 & 0.25 & 0.34 & -0.72 & 0.51 \\
\hline & & PBS & -1.44 & 1.71 & -5.22 & 0.61 & 2.73 & 3.20 & 0.66 & 6.51 \\
\hline & & NW & -1.52 & 1.75 & -5.02 & 0.65 & 2.80 & 3.28 & 0.62 & 6.32 \\
\hline \multirow[t]{4}{*}{ Vontobel } & 11 & Reported & 1.47 & 0.08 & 1.39 & 1.57 & & & & \\
\hline & & Heston & 1.60 & 0.78 & -0.43 & 2.57 & 0.53 & 0.78 & -1.17 & 2.00 \\
\hline & & PBS & -1.92 & 2.13 & -6.23 & 0.76 & 3.38 & 3.97 & 0.63 & 7.78 \\
\hline & & NW & -1.68 & 1.72 & -4.32 & 0.98 & 3.15 & 3.57 & 0.41 & 5.87 \\
\hline \multirow[t]{7}{*}{ Overall } & 213 & Reported & 1.10 & 1.10 & 0.02 & 3.50 & & & & \\
\hline & & Heston & 1.35 & 0.91 & -0.42 & 3.25 & 0.36 & 0.43 & 1.17 & 2.00 \\
\hline & & PBS & -1.68 & 2.02 & -9.03 & 2.10 & 2.78 & 3.38 & -0.03 & 9.60 \\
\hline & & NW & -1.70 & 2.07 & -9.42 & 2.17 & 2.17 & 2.80 & -0.18 & 9.69 \\
\hline & & & & & Mean & $p$ value & & & & \\
\hline & & Reported & - Hesto & & -0.25 & 0.18 & & & & \\
\hline & Rep & prted - He & ston $(\mathrm{Nc}$ & Adj.) & -0.45 & $0.05^{* *}$ & & & & \\
\hline
\end{tabular}

The table shows summary statistics of reported and model-based annualized gross margins for capped bonus certificates. "Reported - Model" is defined as the reported gross margin in \% p.a. minus model-based gross margin in \% p.a. Assuming independence of the pricing errors across issuers and pricing dates, we perform a weighted paired $t$-test to investigate significance of the overall deviation of reported and model-based gross margins. In the bottom line, we also test for significance of the pricing deviations if the correlation adjustment from Section 4.7 is omitted. Robust standard errors are shown in parentheses and significance at a $95 \%$ level is indicated by ${ }^{* *}$.

\subsection{Explaining Gross Margin Differences by Characteristics}

Splitting up the data set into subsamples may help to identify individual issuer differences of reported and model-based gross margins, but it does not provide particular insights into dependencies on security characteristics. To test for this relation, we regress gross margin differences, that is, reported gross margins minus model-based gross margins, on characteristics such as the product lifetime, cap, bonus and barrier level. By default, assuming issuers use a pricing approach similar to ours, we do not expect that differences in gross margins are function of the mentioned variables. However, if we find such a dependency, this may have two possible reasons-first, our pricing approach may yield a systematic under- or overpricing for certain moneyness/maturity combinations resulting from the shape of the fitted volatility surface function. Secondly, it can be an indicator for additional hedging costs charged by issuers for some certificates, for example, those with extreme moneyness.

Overall, as our results are very robust with regard to the employed option pricing model for discounters and the Heston model is the most reasonable approach for capped bonus certificates, we only state regression results for the stochastic volatility model. In Panel A of Table 4, we report 
results from regressing Heston gross margin differences derived for discount certificates on the time-to-expiry, cap moneyness, that is, the cap level standardized by the DAX index value at issuance, and issuer dummies. We consider six different regression setups to illustrate robustness of our findings - in the first three designs (1-3), the gross margin differences are regressed straightforward on all combinations of characteristics. To control for the strong issuer heterogeneity, we additionally control for issuer fixed effects in the regression designs (4-6).

Table 4. Regression Analysis of Gross Margin Differences.

\begin{tabular}{|c|c|c|c|c|c|c|}
\hline \multirow[b]{2}{*}{ Variable } & \multicolumn{6}{|c|}{$\begin{array}{c}\text { Panel A: Discount Certificates } \\
\text { Dependent Variable: Reported Gross Margin - Heston Gross Margin }\end{array}$} \\
\hline & $(1)$ & (2) & (3) & (4) & (5) & (6) \\
\hline Const. & $\begin{array}{c}0.0012 \\
(0.0012)\end{array}$ & $\begin{array}{c}0.0128^{* * *} \\
(0.0017)\end{array}$ & $\begin{array}{l}0.0159 * * * \\
(0.0020)\end{array}$ & & & \\
\hline Time-To-Maturity & $\begin{array}{l}-0.0019 * * \\
(0.0009)\end{array}$ & & $\begin{array}{l}-0.0021^{* * *} \\
(0.0008)\end{array}$ & $\begin{aligned}-0.0039 * * * \\
(0.0005)\end{aligned}$ & & $\begin{aligned}-0.0040^{* * *} & (0.0005)\end{aligned}$ \\
\hline Cap / DAX & & $\begin{array}{l}-0.0146^{* * *} \\
(0.0019)\end{array}$ & $\begin{array}{l}-0.0149 * * * \\
(0.0018)\end{array}$ & & $\begin{aligned}-0.0157 * * * \\
(0.0015)\end{aligned}$ & $\begin{aligned}-0.0158^{* * *} & (0.0014)\end{aligned}$ \\
\hline Issuer Fixed Effects & No & No & No & Yes & Yes & Yes \\
\hline $\mathrm{N}$ & 501 & 501 & 501 & 501 & 501 & 501 \\
\hline Adj. $R^{2}$ & 0.01 & 0.09 & 0.10 & 0.57 & 0.61 & 0.65 \\
\hline \multirow[b]{2}{*}{ Variable } & \multicolumn{6}{|c|}{$\begin{array}{l}\text { Panel B: Capped Bonus Certificates } \\
\text { endent Variable: Reported Gross Margin - Heston Gross Margin }\end{array}$} \\
\hline & (1) & (2) & (3) & (4) & (5) & $(6)$ \\
\hline Const. & $\begin{array}{c}0.0007 \\
(0.0006)\end{array}$ & $\begin{array}{c}0.0156^{* * *} \\
(0.0038)\end{array}$ & & & & \\
\hline Time-To-Maturity & $\begin{array}{c}-0.0036^{* * *} \\
(0.0006)\end{array}$ & $\begin{array}{c}-0.0040 * * * \\
(0.0006)\end{array}$ & $\begin{array}{c}-0.0040^{* * *} \\
(0.0005)\end{array}$ & & & $\begin{array}{c}-0.0045^{* * *} \\
(0.0004)\end{array}$ \\
\hline Bonus / DAX & & $\begin{array}{c}-0.0060 * * * \\
(0.0018)\end{array}$ & & $\begin{array}{c}-0.0131^{* * *} \\
(0.0039)\end{array}$ & & $\begin{array}{c}-0.0109 * * * \\
(0.0027)\end{array}$ \\
\hline Barrier / DAX & & $\begin{array}{c}-0.0108^{* * *} \\
(0.0042)\end{array}$ & & & $\begin{array}{l}-0.0013 \\
(0.0029)\end{array}$ & $\begin{array}{c}-0.0129 * * * \\
(0.0027)\end{array}$ \\
\hline Issuer Fixed Effects & No & No & Yes & Yes & Yes & Yes \\
\hline $\mathrm{N}$ & 213 & 213 & 213 & 213 & 213 & 213 \\
\hline Adj. $R^{2}$ & 0.14 & 0.21 & 0.51 & 0.44 & 0.34 & 0.62 \\
\hline
\end{tabular}

This table reports the results of regressing gross margin differences for the Heston model, that is, reported gross margin minus Heston gross margin, on characteristics and issuer dummies. Robust standard errors are shown in parentheses and significance at a $99 \%(95 \%)$ level is indicated by ${ }^{* * *}\left({ }^{* *}\right)$. Note that all coefficients relate to decimals, for example, a time-to-maturity slope coefficient of -0.0019 should be interpreted as a $0.19 \%$ smaller margin difference for a one year longer maturity.

For discount certificates, there is both a significant dependency of Heston gross margin differences on the product lifetime and the cap level. In our sample, we find that differences between the reported and the Heston margin are slightly smaller for certificates with a longer time-to-maturity. However, as indicated by the changes in the $R^{2}$, the product lifetime only explains little parts of the variation. Furthermore, our pricing differences seem to be negatively related to the cap level which means that we have smaller margin differences for products with a higher cap level. One explanation for this might be that issuers charge higher hedging costs for certificates with low (For an overview on the distribution of cap, bonus and barrier levels in our analyzed sample, see Figure A2 in the appendix.) caps as the issuer guarantees investors a fixed payoff even in times of strongly declining markets.

Regarding capped bonus certificates in Table 4, Panel B, we obtain very similar results compared to the discount certificates. Also here, we observe a negative relation of margin differences and the span of product lifetime. As capped bonus certificates include a down-and-out put and a call option, 
we have the bonus and barrier level as regressors additional to the time-to-maturity. Also for the more exotic certificates, we have a strong negative relation of the "strike", this means barrier and bonus level, and the differences obtained from reported and model-based margins. As capped bonus certificates also work as some kind of safety buffer, higher applied hedging costs for low barriers are conceivable.

\section{Robustness}

Following the definition, the Issuer Estimated Value consists of a model price of the product components adjusted for finance income and hedging costs. Nevertheless, the definition of hedging costs in particular has weak points as the fairness code only states it includes "trading costs or bid-ask spreads" [18], which are not specified any further. In this study, however, we try to closely follow the definitions while revealing the technical pricing process with all related assumptions as transparent as possible. However, the consideration of hedging costs in terms of a volatility charge for short call options of $0.62 \%$ as shown in Section 4.7 potentially drives the results of our empirical study.

To address these concerns, we repeat the pricing procedure and systematically vary the inputs accounting for the occurring hedging costs while leaving all other assumptions fixed. As shown in Section 5, the impact of the pricing model does not play a noteworthy role for discount certificates and the Heston model is the most suitable model for pricing barrier features-thus, we only report results for the Heston model in this robustness analysis. In the following, we consider four different scenarios: firstly, we have the default assumption of the volatility charge of $0.62 \%$ that is derived from the median bid-ask spread of EUREX call options in the prior month September 2015. Then, we regard two variations of this number where we increase (decrease) the volatility charge by $30 \%$ to $0.81 \%$ $(0.43 \%)$ to illustrate the impact of a different input at this place. Finally, we also implement the case of a zero volatility charge. For an illustration of the impact of hedging costs, we derive the relative contribution of the volatility change ( $\mathrm{RCoVC}$ ) by the percentage reduction of the gross margin when a volatility change is applied. This means we compare the Heston gross margin derived with a volatility charge to those computed without any.

For discount certificates, Table 5 shows summary statistics of gross margins derived from the Heston model with varying assumptions $(+0 \%,-30 \%,+30 \%$ and $-100 \%)$ on the default volatility charge of $0.62 \%$. Same as in Table 2 , these figures can be compared to the reported values. In total, we find that a $30 \%$ increase or decrease of the volatility charge does not change the conclusions made in the result Section 5 . For instance, a 30\% higher volatility charge decreases the overall Heston gross margin from $0.53 \%$ p.a. to $0.46 \%$ p.a., and vice versa, a $30 \%$ reduction yields an overall mean annualized Heston gross margin of $0.60 \%$. The effect on Heston gross margins is similar across individual issuers. In case when no volatility charge is considered, then the average overall Heston gross margin rises to $0.77 \%$ p.a. However, as argued in Section 4 , the issuer likely faces some sort of hedging costs and the $0.77 \%$ can be considered as an upper bound on the results for the Heston model.

Regarding the capped bonus certificates, we find a similar impact of volatility charge variations on the Heston gross margins as we observed for the discounters. As shown in Table 6, we find that a 30\% increase of the hedging costs arising from trading the call option leads to an average Heston gross margin of $1.28 \%$ while a $30 \%$ reduction contributes to a $1.42 \%$ model-based gross margin. When we do not account for hedging costs occurring when the call option is shorted, then we find an average of $1.58 \%$ p.a. In relative terms, a variation of the volatility charge has a slightly smaller effect on the figures for capped bonus certificates as the overall absolute level is higher. 
Table 5. Impact of Hedging Costs on Heston Margins (Discount Certificates).

\begin{tabular}{|c|c|c|c|c|c|c|c|}
\hline \multirow[b]{2}{*}{ Issuer } & \multirow[b]{2}{*}{$\mathbf{N}$} & & \multicolumn{4}{|c|}{ Gross Margin in \% p.a. } & \multirow[b]{2}{*}{ RCoVC } \\
\hline & & & Mean & Std. & Min. & Max. & \\
\hline \multirow[t]{5}{*}{ BNP Paribas } & \multirow[t]{5}{*}{17} & Reported & 1.41 & 0.10 & 1.34 & 1.66 & \\
\hline & & Heston $(0.62 \% \mathrm{VC})$ & 2.10 & 0.08 & 2.00 & 2.26 & $-11 \%$ \\
\hline & & Heston $(0.00 \%$ VC) & 2.36 & 0.08 & 2.27 & 2.26 & $0 \%$ \\
\hline & & Heston $(0.43 \% \mathrm{VC})$ & 2.18 & 0.08 & 2.08 & 2.34 & $-8 \%$ \\
\hline & & Heston $(0.81 \%$ VC) & 2.03 & 0.08 & 1.92 & 2.19 & $-14 \%$ \\
\hline \multirow[t]{5}{*}{ Citigroup } & \multirow[t]{5}{*}{73} & Reported & 0.68 & 0.12 & 0.31 & 0.82 & \\
\hline & & Heston $(0.62 \%$ VC) & 0.64 & 0.57 & 0.03 & 1.92 & $-27 \%$ \\
\hline & & Heston $(0.00 \% \mathrm{VC})$ & 0.88 & 0.56 & 0.24 & 2.13 & $0 \%$ \\
\hline & & Heston $(0.43 \%$ VC) & 0.71 & 0.57 & 0.09 & 1.98 & $-19 \%$ \\
\hline & & Heston $(0.81 \%$ VC) & 0.57 & 0.57 & -0.04 & 1.85 & $-35 \%$ \\
\hline \multirow[t]{5}{*}{ Commerzbank } & \multirow[t]{5}{*}{144} & Reported & 0.05 & 0.01 & 0.04 & 0.08 & \\
\hline & & Heston $(0.62 \%$ VC) & 0.43 & 0.55 & -0.12 & 1.39 & $-35 \%$ \\
\hline & & Heston $(0.00 \%$ VC) & 0.66 & 0.55 & 0.02 & 1.58 & $0 \%$ \\
\hline & & Heston $(0.43 \%$ VC) & 0.50 & 0.55 & -0.06 & 1.45 & $-24 \%$ \\
\hline & & Heston $(0.81 \%$ VC) & 0.36 & 0.54 & -0.17 & 1.34 & $-45 \%$ \\
\hline \multirow[t]{5}{*}{ Deutsche Bank } & \multirow[t]{5}{*}{45} & Reported & 0.11 & 0.23 & 0.02 & 0.81 & \\
\hline & & Heston $(0.62 \%$ VC) & 0.40 & 0.30 & -0.07 & 1.04 & $-38 \%$ \\
\hline & & Heston $(0.00 \%$ VC) & 0.64 & 0.31 & 0.09 & 1.30 & $0 \%$ \\
\hline & & Heston $(0.43 \%$ VC) & 0.47 & 0.30 & -0.02 & 1.12 & $-27 \%$ \\
\hline & & Heston $(0.81 \%$ VC) & 0.33 & 0.30 & -0.11 & 0.97 & $-48 \%$ \\
\hline \multirow[t]{5}{*}{ DZ Bank } & \multirow[t]{5}{*}{62} & Reported & 0.01 & 0.00 & 0.00 & 0.02 & \\
\hline & & Heston $(0.62 \% V C)$ & 0.58 & 0.16 & 0.27 & 0.92 & $-31 \%$ \\
\hline & & Heston $(0.00 \%$ VC) & 0.84 & 0.17 & 0.47 & 1.18 & $0 \%$ \\
\hline & & Heston $(0.43 \%$ VC) & 0.65 & 0.16 & 0.33 & 1.00 & $-23 \%$ \\
\hline & & Heston $(0.81 \% \mathrm{VC})$ & 0.50 & 0.15 & 0.21 & 0.84 & $-40 \%$ \\
\hline \multirow[t]{5}{*}{ Goldman Sachs } & \multirow[t]{5}{*}{20} & Reported & 0.73 & 0.03 & 0.69 & 0.77 & \\
\hline & & Heston $(0.62 \%$ VC) & 0.39 & 0.07 & 0.27 & 0.57 & $-37 \%$ \\
\hline & & Heston $(0.00 \%$ VC) & 0.62 & 0.10 & 0.47 & 0.84 & $0 \%$ \\
\hline & & Heston $(0.43 \%$ VC) & 0.45 & 0.08 & 0.35 & 0.66 & $-27 \%$ \\
\hline & & Heston $(0.81 \%$ VC) & 0.32 & 0.07 & 0.19 & 0.49 & $-48 \%$ \\
\hline \multirow[t]{5}{*}{ HSBC } & \multirow[t]{5}{*}{85} & Reported & 0.18 & 0.04 & 0.04 & 0.27 & \\
\hline & & Heston $(0.62 \%$ VC) & 0.35 & 0.13 & 0.00 & 0.66 & $-41 \%$ \\
\hline & & Heston $(0.00 \%$ VC) & 0.59 & 0.16 & 0.17 & 0.94 & $0 \%$ \\
\hline & & Heston $(0.43 \%$ VC) & 0.42 & 0.14 & 0.05 & 0.74 & $-29 \%$ \\
\hline & & Heston $(0.81 \%$ VC) & 0.28 & 0.12 & -0.05 & 0.58 & $-53 \%$ \\
\hline \multirow[t]{5}{*}{ Vontobel } & \multirow[t]{5}{*}{55} & Reported & 1.58 & 0.31 & 1.38 & 2.20 & \\
\hline & & Heston $(0.62 \%$ VC) & 0.57 & 0.55 & -0.33 & 1.55 & $-31 \%$ \\
\hline & & Heston $(0.00 \%$ VC) & 0.83 & 0.56 & -0.07 & 1.82 & $0 \%$ \\
\hline & & Heston $(0.43 \%$ VC) & 0.65 & 0.55 & -0.26 & 1.63 & $-22 \%$ \\
\hline & & Heston $(0.81 \% \mathrm{VC})$ & 0.49 & 0.55 & -0.41 & 1.47 & $-41 \%$ \\
\hline \multirow[t]{5}{*}{ Overall } & \multirow[t]{5}{*}{501} & Reported & 0.40 & 0.54 & 0.00 & 2.20 & \\
\hline & & Heston $(0.62 \%$ VC) & 0.53 & 0.53 & -0.33 & 2.26 & $-31 \%$ \\
\hline & & Heston $(0.00 \%$ VC) & 0.77 & 0.53 & -0.07 & 2.53 & $0 \%$ \\
\hline & & Heston $(0.43 \%$ VC) & 0.60 & 0.53 & -0.26 & 2.34 & $-22 \%$ \\
\hline & & Heston $(0.81 \%$ VC) & 0.46 & 0.52 & -0.41 & 2.19 & $-40 \%$ \\
\hline
\end{tabular}

Across issuers, we report summary statistics of reported Heston gross margins for discount certificates. Throughout this study, we consider hedging costs in terms of a $0.62 \%$ volatility charge (VC) derived from median call option bid-ask spreads as a default case. To show robustness, we increase/decrease this charge by $30 \%$, and finally also consider the case where the volatility charge is set to zero. For an illustration of the impact of hedging costs, we derive the relative contribution of the volatility change (RCoVC) by the percentage reduction of the gross margin when a volatility change is applied. 
Table 6. Impact of Hedging Costs on Heston Margins (Capped Bonus Certificates).

\begin{tabular}{|c|c|c|c|c|c|c|c|}
\hline \multirow[b]{2}{*}{ Issuer } & \multirow[b]{2}{*}{$\mathbf{N}$} & & \multicolumn{4}{|c|}{ Gross Margin in \% p.a. } & \multirow[b]{2}{*}{ RCoVC } \\
\hline & & & Mean & Std. & Min. & Max. & \\
\hline \multirow[t]{5}{*}{ BNP Paribas } & \multirow[t]{5}{*}{58} & Reported & 2.73 & 0.52 & 2.29 & 3.51 & \\
\hline & & Heston $(0.62 \%$ VC) & 2.67 & 0.35 & 2.10 & 3.25 & $-8 \%$ \\
\hline & & Heston $(0.00 \% \mathrm{VC})$ & 2.89 & 0.36 & 2.36 & 3.48 & $0 \%$ \\
\hline & & Heston $(0.43 \% \mathrm{VC})$ & 2.74 & 0.36 & 2.19 & 3.30 & $-5 \%$ \\
\hline & & Heston $(0.81 \%$ VC) & 2.60 & 0.35 & 2.04 & 3.15 & $-10 \%$ \\
\hline \multirow[t]{5}{*}{ Deutsche Bank } & \multirow[t]{5}{*}{49} & Reported & 0.42 & 0.20 & 0.02 & 0.68 & \\
\hline & & Heston $(0.62 \%$ VC) & 0.84 & 0.16 & 0.32 & 1.12 & $-22 \%$ \\
\hline & & Heston $(0.00 \%$ VC) & 1.08 & 0.16 & 0.54 & 1.28 & $0 \%$ \\
\hline & & Heston $(0.43 \%$ VC) & 0.91 & 0.16 & 0.37 & 1.17 & $-16 \%$ \\
\hline & & Heston $(0.81 \%$ VC) & 0.77 & 0.17 & 0.24 & 1.10 & $-29 \%$ \\
\hline \multirow[t]{5}{*}{ DZ Bank } & \multirow[t]{5}{*}{77} & Reported & 0.20 & 0.01 & 0.20 & 0.22 & \\
\hline & & Heston $(0.62 \%$ VC) & 0.62 & 0.21 & 0.12 & 1.06 & $-28 \%$ \\
\hline & & Heston $(0.00 \% \mathrm{VC})$ & 0.86 & 0.22 & 0.36 & 1.24 & $0 \%$ \\
\hline & & Heston $(0.43 \%$ VC) & 0.69 & 0.21 & 0.19 & 1.13 & $-50 \%$ \\
\hline & & Heston $(0.81 \%$ VC) & 0.54 & 0.21 & 0.07 & 1.03 & $-6 \%$ \\
\hline \multirow[t]{5}{*}{ Goldman Sachs } & \multirow[t]{5}{*}{18} & Reported & 1.28 & 0.02 & 1.27 & 1.31 & \\
\hline & & Heston $(0.62 \%$ VC) & 1.44 & 0.30 & 0.80 & 1.99 & $-13 \%$ \\
\hline & & Heston $(0.00 \% \mathrm{VC})$ & 1.65 & 0.28 & 1.04 & 2.14 & $0 \%$ \\
\hline & & Heston $(0.43 \%$ VC) & 1.51 & 0.30 & 0.88 & 2.04 & $-8 \%$ \\
\hline & & Heston $(0.81 \%$ VC) & 1.40 & 0.31 & 0.75 & 1.94 & $-15 \%$ \\
\hline \multirow[t]{5}{*}{ Vontobel } & \multirow[t]{5}{*}{11} & Reported & 1.47 & 0.08 & 1.39 & 1.57 & \\
\hline & & Heston $(0.62 \%$ VC) & 1.60 & 0.78 & -0.43 & 2.57 & $-9 \%$ \\
\hline & & Heston $(0.00 \% \mathrm{VC})$ & 1.76 & 0.73 & -0.17 & 2.69 & $0 \%$ \\
\hline & & Heston $(0.43 \%$ VC) & 1.64 & 0.76 & -0.35 & 2.60 & $-7 \%$ \\
\hline & & Heston $(0.81 \%$ VC) & 1.55 & 0.78 & -0.50 & 2.52 & $-12 \%$ \\
\hline \multirow[t]{5}{*}{ Overall } & \multirow[t]{5}{*}{213} & Reported & 1.10 & 1.10 & 0.02 & 3.50 & \\
\hline & & Heston $(0.62 \% V C)$ & 1.35 & 0.91 & -0.42 & 3.25 & $-15 \%$ \\
\hline & & Heston $(0.00 \%$ VC) & 1.58 & 0.90 & -0.17 & 3.48 & $0 \%$ \\
\hline & & Heston $(0.43 \%$ VC) & 1.42 & 0.91 & -0.36 & 3.30 & $-10 \%$ \\
\hline & & Heston $(0.81 \%$ VC) & 1.28 & 0.91 & -0.50 & 3.16 & $-19 \%$ \\
\hline
\end{tabular}

Across issuers, we report summary statistics of reported and Heston gross issuer margins for capped bonus certificates. Throughout this study, we consider hedging costs in terms of a $0.62 \%$ volatility charge (VC) derived from median call option bid-ask spreads as a default case. To show robustness, we increase/decrease this charge by $30 \%$, and finally also consider the case where the volatility charge is set to zero. For an illustration of the impact of hedging costs, we derive the relative contribution of the volatility change (RCoVC) by the percentage reduction of the gross margin when a volatility change is applied.

For all products and issuers, Tables 5 and 6 also well-illustrate the strong relative influence of hedging costs on expected gross margins, ranging down to $-40 \%$ for discounters and $-19 \%$ for capped bonus certificates. The intuition is that supposed bid-ask spreads from options traded at exchanges, such as the EUREX, can be large in Euro terms and as the issuers gross margin is a small residual on top of some fair value, the effect on gross margins is leveraged. This effect, of course, is larger for certificates with smaller charged gross margins as we can see for the HSBC subsample in Table 5 where the increased hedging costs shrink the mean gross margin derived from the Heston model by $-41 \%$.

\section{Conclusions}

Individualized payoff profiles and low transaction costs make retail structured products appealing for many private investors. However, as short selling is prohibited and issuers are typically market-makers of these products, high margins can be potentially realized by overpricing as already indicated by several empirical studies. In May 2014, the Deutscher Derivate Verband and issuing banks decided to provide more transparency by disclosing the Issuer Estimated Value, a fair value of 
the certificates designed to reflect the market price of the product among professionals. By publishing the Issuer Estimated Value, banks implicitly make a statement on their expected gross margin and, as a first paper, we provide an empirical analysis on the fairness and market-consistency of these figures. While in 2018 the IEV has been replaced by similar margin and cost statements, our results should still be a good proxy on these new key figures. We will discuss this in more detail below.

We have several findings-firstly, we deduce that reported gross margins vary considerably across issuers even on standard retail products such as the discount and capped bonus certificates which is a surprising finding in such a competitive market. Secondly, we are able to verify the disclosed gross margins using the stochastic volatility model of Heston, the Practitioner Black-Scholes model and the Nadaraya-Watson approach. Overall, observed discrepancies seem to be essentially insignificant even if the correlation adjustment from Section 4.7 is omitted. As we are facing a high methodological uncertainty in general, our strategy is to make the pricing process as transparent as possible and to show sensitivities of our main inputs. In particular, additional price components of the Issuer Estimated Value, such as hedging and trading costs, require additional assumptions making the pricing potentially prone to misspecifications. To reduce concerns regarding the incorporation of these hedging costs, we provide robustness tests where the volatility charge is varied. Finally, we find that $\mathrm{a} \pm 30 \%$ variation of these hedging costs and the choice of the option pricing model do not change our main finding that the plausibility of the bank's disclosed margins can be validated in our sample.

Therefore the answer to our question raised in the present paper's title is a careful initial 'yes' - on the one hand, we are able to verify the stated gross margins pretty closely. Observed deviations can be explained be variations in the pricing models and by the fact that the hedging books of the considered issuers are surely not all the same. That means that due to other transactions (e.g., due to institutional derivative flow) some issuers might be more or less keen to sell retail structured products with certain characteristics (like strike, maturities, etc.) and therefore see their fair value differently. On the other hand, as can be seen by considering that competition in this market has risen over the years and margins have accordingly declined (see the literature overview in the introduction), our observed deviations in the reported margins might still be too large for some readers to accept as consistent and fair. Therefore, future research should focus on larger samples and timeframes than our present initial study.

As mentioned before, the concept of the IEV has been discontinued in 2018 as the new European regulation for Packaged Retail and Insurance-based Investment Products (PRIIPs, see Reference [36]) already leads to new product information sheets which have to contain information about all costs related to these kind of products. In particular, each information sheet has to specify what kind of absolute and percentage costs are associated with buying a structured product, holding and selling it. If one assumes that an investor holds a discount or a bonus certificate until maturity (which is usually done in these product information sheets), all these kind of costs are usually only of the entry cost type. Therefore, the published numbers directly compare to the products' gross margins investigated in the present paper. Consequently, using these new disclosures might be a good starting point to extend our research.

Author Contributions: All authors contributed equally to the paper. All authors have read and agreed to the published version of the manuscript.

Funding: This research received no external funding.

Acknowledgments: The authors thank the anonymous referees for providing valuable input to significantly improve the present paper.

Conflicts of Interest: The authors declare no conflict of interest. 


\section{Appendix A}
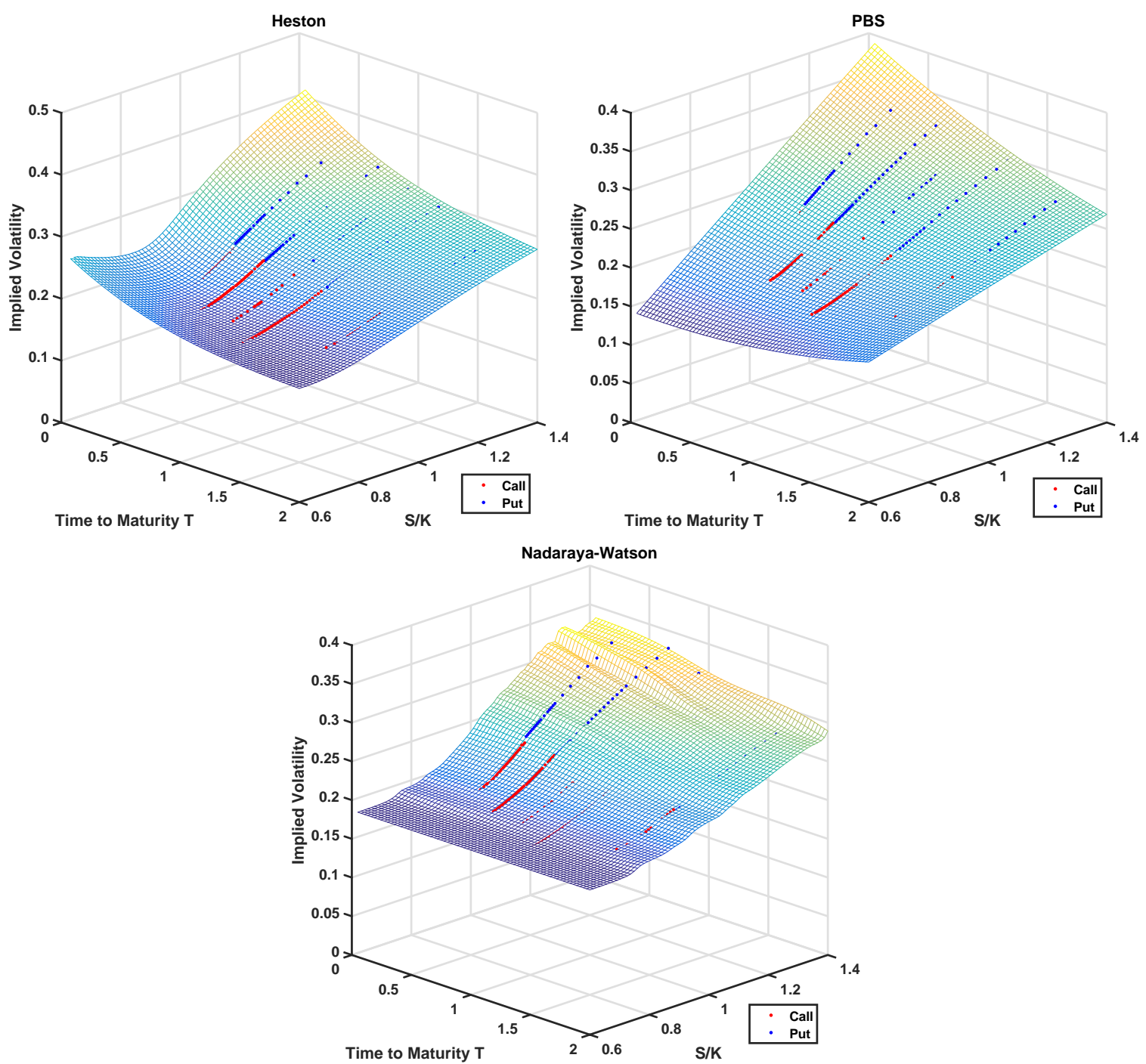

Figure A1. Illustration of Smoothed Implied Volatility Surfaces. Smoothed implied volatility surfaces from Heston, PBS and Nadaraya-Watson on 30 September 2015. 

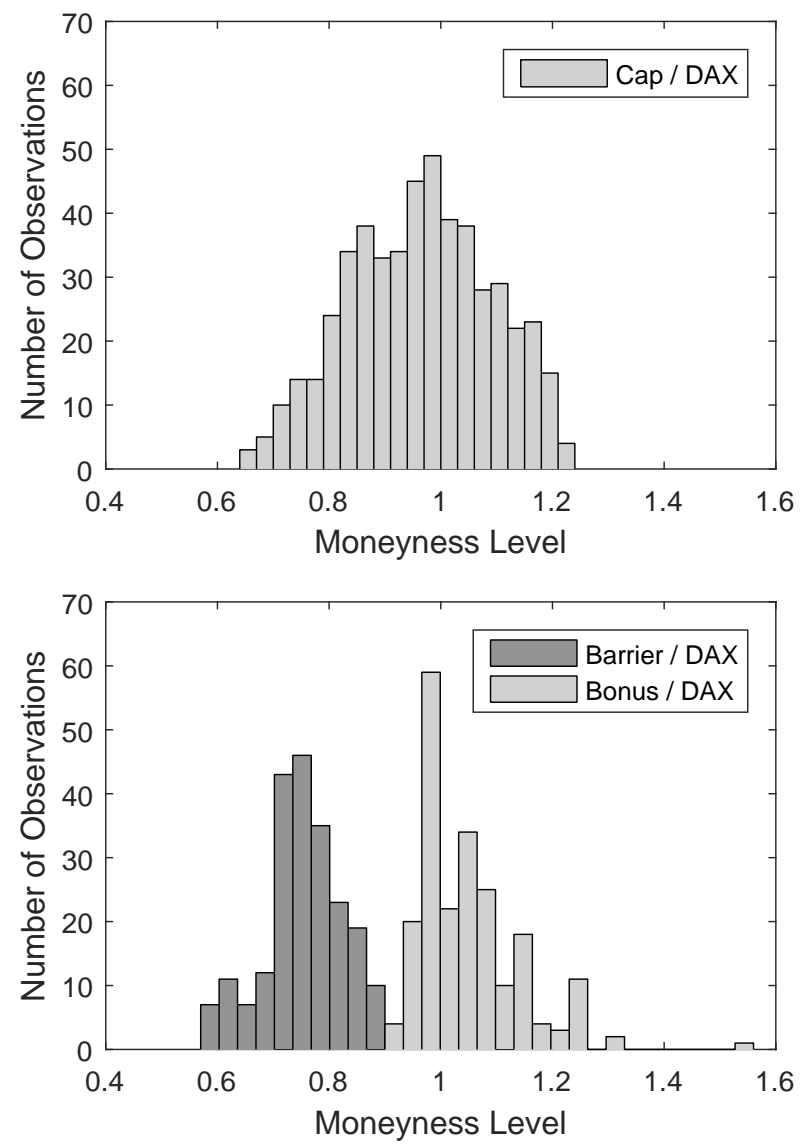

Figure A2. Histogram of Cap, Bonus and Barrier Moneyness. For all discount certificates, we divide the cap value by the end-of-day DAX level at issuance to obtain the "moneyness" of the embedded call option. Correspondingly, we do so for capped bonus certificates with the barrier and bonus level. The upper histogram corresponds to discount certificates and the lower to capped bonus certificates, respectively.

Table A1. Issue Dates, Number of Issued Securities and CDS.

\begin{tabular}{cccc}
\hline Issuer & Date of Issuance & Number of Issued Securities & 1-Year CDS in Basis Points \\
\hline & \multicolumn{3}{c}{ Panel A: Discount Certificates } \\
\hline BNP Paribas & 08-Oct-2015 & 17 & 31.41 \\
Citigroup & 15-Oct-2015 & 73 & 35.12 \\
Commerzbank & 08-Oct-2015 & 83 & 47.86 \\
& 13-Oct-2015 & 61 & 45.56 \\
DZ Bank & 02-Oct-2015 & 48 & 59.70 \\
& 08-Oct-2015 & 5 & 59.70 \\
& 26-Oct-2015 & 5 & 58.71 \\
Deutsche Bank & 28-Oct-2015 & 4 & 58.71 \\
& 09-Oct-2015 & 6 & 43.83 \\
Goldman Sachs & 21-Oct-2015 & 39 & 34.26 \\
& 13-Oct-2015 & 12 & 40.30 \\
HSBC & 30-Oct-2015 & 8 & 34.31 \\
Vontobel * & 30-Sep-2015 & 85 & 44.68 \\
& 05-Oct-2015 & 28 & 37.51 \\
& 12-Oct-2015 & 3 & 28.83 \\
& 26-Oct-2015 & 13 & 26.76 \\
& 27-Oct-2015 & 11 & 28.11 \\
\hline
\end{tabular}


Table A1. Cont.

\begin{tabular}{cccc}
\hline Issuer & Date of Issuance & Number of Issued Securities & 1-Year CDS in Basis Points \\
\hline \multicolumn{4}{c}{ Panel B: Capped Bonus Certificates } \\
\hline BNP Paribas & 15-Oct-2015 & 58 & 31.84 \\
DZ Bank & 30-Sep-2015 & 51 & 59.70 \\
& 08-Oct-2015 & 9 & 59.70 \\
& 15-Oct-2015 & 1 & 58.70 \\
Deutsche Bank & 28-Oct-2015 & 16 & 58.71 \\
Goldman Sachs & 07-Oct-2015 & 49 & 47.66 \\
& 21-Oct-2015 & 8 & 40.94 \\
Vontobel * & 05-Oct-2015 & 10 & 36.65 \\
& 13-Oct-2015 & 6 & 37.51 \\
& 27-Oct-2015 & 1 & 29.54 \\
\hline
\end{tabular}

We report issue dates of all discount and capped bonus certificates in our sample. Additionally, the number of certificates issued, as well as the applied CDS rate (in basis points), is stated for each bank and date. The star $\left(^{*}\right)$ indicates that the Vontobel CDS rates are approximated as explained in Section 4.

\section{References}

1. Deutscher Derivate Verband. Webpage. 2020. Available online: https://www.derivateverband.de/ENG/ Statistics/MarketVolume (accessed on 15 September 2020).

2. Chen, A.H.; Kensinger, J.W. An analysis of market-index certificates of deposit. J. Financ. Serv. Res. 1990, 4, 93-110. [CrossRef]

3. Chen, K.C.; Sears, R.S. Pricing the SPIN. Financ. Manag. 1990, 19, 36-47. [CrossRef]

4. Muck, M. Where should you buy your options? The pricing of exchange traded certificates and OTC-derivatives in Germany. J. Deriv. 2006, 14, 82-96. [CrossRef]

5. Wilkens, S.; Stoimenov, P.A. The pricing of leverage products: An empirical investigation of the German market for long and short stock index certificates. J. Bank. Financ. 2007, 31, 735-750. [CrossRef]

6. Schmitz, P.; Weber, M. Buying and selling behaviour of individual investors in option-like securities. Die Betriebswirtschaft 2012, 72, 409-426.

7. Entrop, O.; Schober, A.; Wilkens, M. The Pricing Policy of Banks for Exchange-Traded Leverage Certificates: Interday and Intraday Effects; University of Passau and University of Augsburg: Passau, Germany, 2013.

8. Baule, R.; Blonski, P. The demand for warrants and issuer pricing strategies. J. Futur. Mark. 2015, 35, 1195-1219. [CrossRef]

9. Wilkens, S.; Erner, C.; Röder, K. The pricing of structured products in Germany. J. Deriv. 2003, 11, 55-69. [CrossRef]

10. Stoimenov, P.A.; Wilkens, S. Are structured products 'fairly' priced? An analysis of the German market for equity-linked instruments. J. Bank. Financ. 2005, 29, 2971-2993. [CrossRef]

11. Black, F.; Scholes, M. The pricing of options and corporate liabilities. J. Polit. Econ. 1973, 81, 637-654. [CrossRef]

12. Baule, R.; Entrop, O.; Wilkens, M. Credit risk and bank margins in structured financial products: Evidence from the German secondary market for discount certificates. J. Futur. Mark. 2008, 28, 376-397. [CrossRef]

13. Hull, J.C.; White, A. The impact of default risk on the prices of options and other derivative securities. J. Bank. Financ. 1995, 19, 299-322. [CrossRef]

14. Baule, R. The order flow of discount certificates and issuer pricing behavior. J. Bank. Financ. 2011, 35, 3120-3133. [CrossRef]

15. Baule, R.; Tallau, C. The pricing of path-dependent structured financial retail products: The case of bonus certificates. J. Deriv. 2011, 18, 54-71. [CrossRef]

16. Heston, S.L. A closed-form solution for options with stochastic volatility with applications to bond and currency options. Rev. Financ. Stud. 1993, 6, 327-343. [CrossRef] 
17. Döhrer, B.; Johanning, L.; Steiner, N.; Völkle, A. Issuer Margins for Structured Products in Germany; Technical Report; Deutscher Derivate Verband. 2013. Available online: https://www.gyc.com.sg/files/p_dohrerissuer.pdf (accessed on 15 September 2020).

18. Deutscher Derivate Verband. Notes to the Fairness Code; Technical Report; Deutscher Derivate Verband. 2015. Available online: https:/ / www.derivateverband.de/DE/MediaLibrary/Document/Fairness\%20Kodex/1848-033\%20Broschuere\%20Erlaeuterungen\%20zum\%20Fairness\%20Kodex\%20EN-Screen-01.pdf (accessed on 15 September 2020).

19. Yuan, S.; Rieger, M.O. Diversification with options and structured products. Rev. Deriv. Res. $2020,36$. [CrossRef]

20. Kim, K.K.; Lim, D.Y. A recursive method for static replication of autocallable structured products. Quant. Financ. 2019, 19, 647-661. [CrossRef]

21. Baule, R.; Münchhalfen, P.; Shkel, D. Offenlegung von fairen Zertifikatepreisen durch den Issuer Estimated Value. In FIRM Jahrbuch; Frankfurt Institute for Risk Management and Regulation: Frankfurt, Germany, 2017; pp. 54-56.

22. Baule, R.; Münchhalfen, P.; Tallau, C. Disclosure Policies for the Issuer Estimated Value-Facts and Fiction. Available online: https://papers.ssrn.com/sol3/papers.cfm?abstract_id=3317499 (accessed on 15 September 2020).

23. Dumas, B.; Fleming, J.; Whaley, R.E. Implied volatility functions: Empirical tests. J. Financ. 1998, 53, $2059-2106$. [CrossRef]

24. Aït-Sahalia, Y.; Lo, A.W. Nonparametric estimation of state-price densities implicit in financial asset prices. J. Financ. 1998, 53, 499-547. [CrossRef]

25. Fengler, M.R. Semiparametric Modeling of Implied Volatility, 1st ed.; Springer Science \& Business Media: Berlin/Heidelberg, Germany, 2006.

26. Cox, J.C.; Ingersoll, J.E.; Ross, S.A. A theory of the term structure of interest rates. Econometrica 1985, 53, 385-407. [CrossRef]

27. Lewis, A.L. A Simple Option Formula for General Jump-Diffusion and other Exponential Léry Processes; Technical Report; Envision Financial Systems and OptionCity.net. 2001. Available online: http:/ /www.optioncity.net/ pubs/explevy.pdf (accessed on 15 September 2020).

28. Albrecher, H.; Mayer, P.; Schoutens, W.; Tistaert, J. The little Heston trap. Wilmott Mag. 2007, 3, 83-92.

29. Andersen, L.; Brotherton-Ratcliffe, R. Extended Libor Market Models with Stochastic Volatility; Technical Report; Bank of America Merrill Lynch and Gen Re Securities. 2001. Available online: http:/ / www.globalriskguard. com/resources / fideriv / andersen.pdf (accessed on 15 September 2020).

30. Boyle, P.; Broadie, M.; Glasserman, P. Monte Carlo methods for security pricing. J. Econ. Dyn. Control. 1997, 21, 1267-1321. [CrossRef]

31. Rubinstein, M.; Reiner, E. Breaking down the barriers. Risk 1991, 4, 19-35.

32. Broadie, M.; Glasserman, P.; Kou, S.G. A continuity correction for discrete barrier options. Math. Financ. 1997, 7, 325-349. [CrossRef]

33. Christoffersen, P.; Jacobs, K. The importance of the loss function in option valuation. J. Financ. Econ. 2004, 72, 291-318. [CrossRef]

34. Kyprianou, A.; Schoutens, W.; Wilmott, P. Exotic Option Pricing and Advanced Lévy Models; John Wiley \& Sons: Chichester, UK, 2006.

35. Schoutens, W.; Simons, E.; Tistaert, J. Chapter A perfect calibration! Now what? In The Best of Wilmott; Wiley: Hoboken, NJ, USA, 2003; pp. 281-304.

36. European Commission. Webpage. 2020. Available online: https://ec.europa.eu/info/business-economy-euro/ banking-and-finance/consumer-finance-and-payments/retail-financial-services/key-information-documentspackaged-retail-and-insurance-based-investment-products-priips_en (accessed on 15 September 2020).

(C) 2020 by the authors. Licensee MDPI, Basel, Switzerland. This article is an open access article distributed under the terms and conditions of the Creative Commons Attribution (CC BY) license (http:/ / creativecommons.org/licenses/by/4.0/). 